\title{
IMPACT OF ORGANIZATIONAL VALUE SYSTEM, PERCEIVED ORGANIZATIONAL SUPPORT AND JOB SATISFACTION ON ORGANIZATIONAL COMMITMENT
}

\section{Maha Sadaf ${ }^{*}$, Usman Mukhtar², Ali Raza Nemati ${ }^{3}$, Rehan Yousaf ${ }^{4}$ and Wasmiya Javed ${ }^{5}$}

\begin{abstract}
This paper aims to investigate the effects of perceived organizational support, organizational values system, and job satisfaction on organizational commitment. The study has been conducted in the educational sector of Pakistan. Building on the previous literature, the authors propose a model which links an organization's internal procedures/practices, employees' perceptions, views, and his/her level of contentment with his job with his/her loyalty and emotions. Through the assumed connections between these aspects, the relationship among them was inspected and analyzed in the given study. To test the proposed model, the data was collected online from 210 faculty members and teachers from different universities in Pakistan. It was accomplished through convenient sampling. Moreover, a cross-sectional method was adopted for data gathering. As per the author's assumptions, the results generated through regression analysis provide shreds of evidence that there exists a significant positive relationship between organizational commitment, job satisfaction, organizational values, and perceived organizational support. The overall study displays the importance of providing support, improving job satisfaction, and clearly defining organizational values to the employees to enhance their organizational commitment. The study validates the significance of organizational practices over employees' attachment towards the organization and deepens the understanding of the determinants of organizational commitment. Furthermore, suggestions about theoretical and managerial practices of the given study have been discussed in the end.
\end{abstract}

Keywords: Organizational Commitment; Job Satisfaction; Organizational Values.

\footnotetext{
${ }^{1}$ Student, Bahria University Islamabad, Pakistan. Email: sadafmaha73@gmail.com

${ }^{2}$ Student, Bahria University, Islamabad, Pakistan. Email: umukhtar404@gmail.com

${ }^{3}$ Director Human Resources \& Organizational Development, TMUC Pakistan and The Millennium Education Group. Email: alirazanemati@gmail.com

${ }^{4}$ Student, Bahria University Islamabad, Pakistan. Email: rehanyousaf210@gmail.com

${ }^{5}$ Student, Riphah International University, Islamabad, Pakistan. Email: jwasmiya@gmail.com

*Corresponding Author
} 


\section{INTRODUCTION}

In this ever-changing and fiercely competitive environment, a company needs to manage its human resources effectively and maintain good organizational performance. Organizational commitment plays an important role in this area. Research and findings regarding organizational commitment can help organizations enhance their performance. For organizations to keep delivering positive results and achieve their aims, they must keep their employees committed to the organization and build their interest and dedication towards work. As technology is advancing and globalization is increasing it is becoming harder and costlier for organizations to survive. Committed employees will increase the efficiency and efficacy of the organization, whereas uncommitted and unsatisfied one's lead to low productivity, high turnover, counterproductive behavior (Dalal, 2005), loss of profits.

Studies could generate results about practices that could lead to higher levels of commitment. Organizations then could increase these practices that could boost their employee's commitment towards the organization. Several studies were conducted regarding the concept of organizational commitment especially in the field of organizational psychology. Organizational commitment has been under focus by many researchers because it is related to important factors like turnover, absenteeism, job performance, motivation, intent to stay, productivity, and loyalty to the organization in previous studies.

Recent studies show that organizations should focus on enhancing the loyalty of employees not only through financial means but also through emotional and psychological means. Organizations should care for and respect employees to develop a sense of ownership and obligation in them. Organizations should also depend on values and beliefs for improving their employee's commitment. These factors are proved to build employees' sense of identity relative to the organization and their loyalty. Loyal and skilled employees are considered real sources of revenue generation. (Yao, 2019).

Due to the positive impact of organizational commitment on employee behavior, this subject needs to be investigated more. This given study will be carried out in the educational sector of Pakistan. The educational sector can be considered as the foundation for the future. A skilled workforce and educated population can lead the country towards development and increase the quality of life. Many crimes and social issues can be resolved through education. The quality of education in Pakistan is very low. To improve the quality of education, it is essential to keep the administrators 
and especially teachers committed to their organization. The purpose of this study is to analyze the effect of organizational values system, organizational support, and job satisfaction on organizational commitment on teachers and administrators, whether the effect is the same as in other organizations or higher and which factors affect more in this regard to increase the commitment of teachers. Pakistan is a developing country, so the financial rewards contribute more towards job satisfaction and commitment (Abid et al., 2021). This study aims to analyze that how many other factors can contribute to this cause.

Organizational commitment, the centre of attention in our study, can be defined generally as to how much the goals and values of an organization and its employee has been aligned or to what extent they have accepted the goals and values, to what extent they are loyal towards the organization, and to what extent are they keen to put substantial efforts for the achievement of organizational goals. In 1991, this concept was looked at more particularly. A three-component model of commitment was presented by John Meyer and Natalie Allen which describes and distributes commitment into three components namely affective commitment, normative commitment, and continuance commitment.

Affective commitment is the extent to which the employee is emotionally attached and dedicated to their work and organization. The intent is to stay within the organization with their own will and desire. Normative commitment is the reason an employee stays in an organization because he thinks he is morally obligated to. Continuance commitment refers to the intent of an employee to stay in the organization because he feels that the price of leaving is high It plays an important role in the efficacy of an organization. Since most research studies conducted have analyzed the results of the level of commitment on different behaviors, there needs to be more research done regarding the causes of such commitment.

This study, however, is going to explore the influence of Job satisfaction, organizational values, and perceived organizational support on the overall organizational commitment. Questions like how job satisfaction affects employees' loyalty towards work? what is the role of the perception of an employee about care and support from the organization plays in his sincerity and emotions towards the organization? how the communication and implementation of organizational culture and values can influence the devotion of an employee? will be answered by conducting the given research. Presumably, If the employees are satisfied with their job, feel supported in various ways 
by the organization and their values are aligned with the values of the organization, then they would feel that the organization is committed to them and value them and in return, they will value the organization.

One of the previous extensive studies that have been conducted on this subject, suggested that further studies should be conducted that include different organizations of different sizes as small and large organizations may have different organization dynamics. This research is going to include different organizations to further the previous study. There has been researching regarding the relationship between job satisfaction and organizational commitment that was carried out in the educational sector of Pakistan. (Qureshi, 2012). But the causal effects of organizational values and perceived organizational support on organizational commitment have rarely been studied in this sector. Moreover, the effect of these three variables on organizational commitment has not been studied together. As this study does not focus on the different components of organizational commitment separately, further studies can be done to study the impact of these determinants on each of the components of organizational commitment as discussed in Meyer's model.

Many theories formulated in the past have shown that there is a significant relationship between organizational commitment and these variables. In past, Herzberg's two-factor theory has been used to formulate the factors that can lead to job satisfaction. The two factors are known as extrinsic (external) and intrinsic (internal) factors. External factors can satisfy the employee through external rewards related to the job like salary, conditions of the workplace, perks and benefits, relation with others, etc. Similarly, internal factors can satisfy the employee through nonfinancial rewards like recognition, achievement, respect, personal achievement, and growth. (Tan, 2011). Positive and strong correlations have been found between these factors and organizational commitment, specifically with the affective component of commitment. These findings show that their relations are affected by cultural factors as well. (Meyer, 2002). More studies could be found that showed the causal relationship between job satisfaction and commitment. (Aydogdu, 2011).

Researchers have a consensus on the fact that Job satisfaction overall has a significant impact on building commitment. Different researchers related to different fields have focused on different aspects. Psychology researchers focused on the relation of personality traits of Job satisfaction with commitment, whereas others focused on financial and non-financial job rewards and factors related to organization and related them with commitment. 
A theory by Einsenburger, known as organizational support theory, describes, that employee make a perception about how the organization feels about them based on the behavior of employers, managers, and others at upper levels. Researchers have found that when employees believe that the organization supports them and care about them and that the organization is committed to them and will pay them back for their efforts, they feel that they are also obligated to return the favour and be more committed towards the organization. They will prefer to stay in the organization and work more efficiently. This theory is based on the norm of reciprocity.

Vancouver and Schmitt (1991) studied the relation between values and commitment in an educational setting and found that the congruency between a person and organizational values significantly influences the greater the commitment to the organization. In 2001, Elizur and Koslowsky have concluded from studies that strong organizational values are positively correlated with organizational commitment. Similarly, another study found similar results about their relation, which was conducted in Singapore by Putti et al. (1989).

In essence, the given research is going to study the determinants of organizational commitment and their influence on employees' commitment to addressing the issue of decreasing dedication, productivity, and performance of employees within the educational sector of Pakistan. It will be beneficial not only for the educational institutions but applicable to other organizations as well and can assist them in retaining their employees and improving their overall organizational performance. Briefly, the further parts of the paper discuss the literature on organizational commitment and its determinants, including perceived organizational support, organizational values system, and job satisfaction. Based on the review of previous literature, a model is formulated and designed which is supported by the organizational support theory of Eisenberger and Herzberg's two-factor theory. The model is then further tested and analyzed through different statistical tools which are discussed in the methodology section. The end section then discusses the test results and their implications.

\section{LITERATURE REVIEW}

\section{Organizational Commitment}

Organizational commitment is based on the idea of reciprocity in which people choose to join and dedicate their time and energy to an organization and commit to it in exchange for some type of remittance or reward (Alutto et al., 1973). Employees that are committed to the organization are more likely to stay longer and improve their performance, increasing the total productivity of the 
company. High turnover is costly. Hiring new employees, adjusting them in the organization, and training them is not an easy task. Moreover, organizations lose their valuable and skilled employees. Organizational commitment is found to be negatively correlated with turnover and positively correlated with performance (Martin \& Kaufman, 2013). As Mueller et al. (1994) expressed based on their research that "When employees are both satisfied with their jobs and committed to the organization, the bond with the organization will be strengthened and will result in greater cooperation and a reduced likelihood of quitting". These issues may be evident in the educational sector when instructors and other personnel may leave universities due to job discontent and a lack of support from the organization. The universities must retain lecturers with experience and expertise to maintain effective performance (Chughtai \& Zafar, 2006). Liu (2019) stated that when the employees believe in their competencies to perform the job, they will show a higher level of trust towards the organization and positive work behavior. Due to their trust, they will consider aligning their goals with the goals of the organization and as a result their organizational commitment increases.

In the educational sector of Pakistan, a study by Noor (2009) shows that training \& development opportunities, work-life policies, and empowerment practices contribute highly towards commitment. This study provides a strong link between organizational support, organizational citizenship behavior, and commitment. As the lecturers would be given flexible and friendly policies, they would be more comfortable and motivated. Empowerment practices and training and development processes will increase their capability and enhance their skills to deliver better performance. Fatima et al. (2013) found in her studies that empowered employees find their ways to do things, which results in the high level of effectiveness that shows in their work. They can deal with worse situations, be flexible to experience new things, and adapt to changes easily because they are committed to the organization.

Currie and Dollery (2006) in their research also proved that employees are more committed and dedicated towards their organization due to the support they are given by the organization in the form of skills, training, and tuition subsidies. Many types of research provide causes that could lead to higher organizational commitment. Researchers started focusing on the causal factors due to the interest of organizations in developing their employees' commitment. Before the development of interest in causes, researchers focused more on the consequences of commitment (Caldwell et al., 1990). Somers (1995) studied the negative relation between commitment and absenteeism. As the employee is not committed to the organization, he loses interest in his work 
and tries to avoid it. The days of leave increase and his performance deteriorates (Haroon \& Shakil, 2021). In educational settings, absenteeism of teachers could lead to substantial losses of studies for students. The whole purpose of educational organizations depends on delivering quality and proper education to students. Loss in studies defeats the purpose and affects the grades of students (Norton, 1998)

More studies have shown that commitment develops motivation among employees and increases their involvement in their jobs (Farrell \& Rusbult, 1981). As teachers would develop more involvement, they would be able to deliver better lectures and try to cooperate with students (Chughtai \& Zafar, 2006).

\section{Antecedents}

Mayer and Schoorman (1998) found organizational commitment to be positively correlated with retirement benefits. Previous researchers focused more on the personal or job characteristics that affect commitment (Caldwell et al., 1990). Sheldon (1971), concluded through his research in a laboratory setting that works experiences, social involvement, and age factors are positively correlated with organizational commitment. Angle and Perry (1983) investigated the relationship between personal characteristics such as age, tenure, educational level, and organizational commitment and found positive results. The study suggests that as years of services employees provide to organizations increase, their loyalty towards their organization increases. As the bond and relation between employee and organization mature with time, their commitment level progresses. This finding was also supported by another study conducted by Caldwell et al. (1990), who argued that longer tenure does affect commitment but there are strong relations between early work experiences and commitment as well. Their study demonstrated that when an employee enters an organization through proper recruitment procedures and gets adjusted in the organization through the proper socialization process, his commitment tends to be higher. The study also found that a strong reward system and strong organizational values system contribute to the commitment level of employees. Another study conducted in the industrial sector by Miao et al. (2013) shows the impact of extrinsic, intrinsic, and social rewards on affective commitment. Good social security provision, low-cost housing, satisfaction with supervision, coworker's support, and autonomy were found to be strongly correlated with commitment. The contribution of extrinsic reward was much more significant than intrinsic reward except anatomy in the development of commitment. The author stated that due to the difference in the standard of living between China and the west, 
extrinsic rewards are more effective in China. In the context of Pakistan, due to lower standard of living teachers may prefer extrinsic rewards more, but some studies found otherwise (Khan et al., 2011).

\section{Job Satisfaction}

Job satisfaction is defined as a pleasant feeling or an emotion (which is also referred to as affect) of an individual which develops as a consequence of his job assessment or his experiences regarding the job (Locke, 1976). Ivancevich et al. (1990) defined job satisfaction as an attitude that evolves on basis of how the employee perceives his job. The attitude is referred to by some researchers as the focus of the pleasant feeling developed due to job assessment. According to some researchers, an employee could be satisfied or dissatisfied and there is no in-between. (Aydogdu \& Asikgil, 2011). Whereas Herzberg in his theory assumed that if an employee is provided good pay, benefits, bonuses, and a good working environment (extrinsic rewards), he would not be dissatisfied but will not be satisfied as well. If he is provided with good pay, a good working environment, and also challenging work and recognition which contribute towards intrinsic rewards, then he will be satisfied. If he is not provided with any of these rewards, he will be dissatisfied. (Alshmemri et al., 2017).

To discuss job satisfaction, two job characteristics related to intrinsic rewards i.e., autonomy and job variety are important factors. Autonomy is defined as the extent to which the job allows the employee significant flexibility, freedom, and choice in scheduling the work and deciding how it will be completed. (Spector, 1986).

Furthermore, Williamson et al. (2009) argued that if a company gives a high level of autonomy and high pays to its employees, the employees will exhibit a high level of satisfaction and in turn will develop a higher level of the emotional and moral aspect of commitment. They will feel morally obligated to commit to their organization and will stay in the organization because they want to. Autonomy can help teachers to apply their creative ways to teach and deal with students to make them learn in a better way, this will increase their motivation. Teachers will also learn what methods are not useful for teaching (Coelho \& Augusto, 2010). Work variety, another job characteristic that contributes towards Job satisfaction, is the extent to which a job gives freedom to the employee to adopt a variety of options to perform their tasks. It also requires the worker to use different skills (Hackman \& Oldham, 1974). Millette and Gagne (2008) found a strong relationship between job characteristics, job satisfaction, and job performance. He argued that employees are not dedicated enough to their organizations because their job structure restricts them 
from practicing their full potential. Researchers suggest that job characteristics such as autonomy and variety can increase an employee's sense of achievement and self-actualization through their job performance (Bhuian \& Mengue, 2002). These factors create intrinsic motivation of employees and are found to have a strong impact on organizational commitment. (Hunt et al., 1985). Some extrinsic factors that contribute negatively towards overall job satisfaction are workload and pay. Workload among teachers is a big problem in Pakistan. They are given tasks other than teaching like paperwork, duplicating information, monitoring, reporting, etc. Teachers also complain about constantly getting other tasks that significantly increase their workload like too many classes to teach which decreases their non-contact time, lots of supervisory duties, taking shifts of absent staff, and too many students in a class to teach and assess (Butt \& Lance, 2005). Excessive workload has been found to negatively influence job satisfaction and commitment. It creates exhaustion and stress in teachers and negatively influences their personal lives. (Ahuja et al., 2002).

Moreover, pay can be considered one of the most prominent causal factors of job satisfaction and commitment (Iverson \& Roy, 1994). In countries like Pakistan, with a low standard of living, teachers are motivated and get satisfied more by compensation and benefits than other kinds of rewards. (Malik et al., 2010). Job satisfaction can be considered a very important factor to enhance performance and commitment. Other than these outcomes, productivity can be considered as a significant outcome of job satisfaction. The employees feel that their efforts are appreciated through extrinsic and intrinsic rewards, so they work harder and more attentively which increases productivity. Employees exhibiting high satisfaction are found to have better mental and physical health. They try to perform better than what is expected of them, adapt, and learn new skills in less time (Sonia, 2010). Many other types of research and studies have also proven that job satisfaction is a universal predictor of commitment (Mathur \& Salunke, 2013).

\section{H1: Job satisfaction has a positive impact on organizational commitment.}

\section{Perceived Organizational Support}

Perceived organizational support can be defined as the degree to which employees think that they are being valued and taken care of by the organization (Eisenberger et al., 1986). A great deal of attention has been given to organizational support by researchers. They assumed that based on the reciprocity norm, an employee will become more committed and dedicated towards the organization if he thinks the organization values him and supports him (Eisenberger et al., 2002). 
Cheung (2000) conducted a study in Taiwan to find out the effects of cultural differences on the relationship between organizational support and commitment. They found a strong correlation between organizational support and organizational commitment, particularly with the emotional aspect of commitment. He stated that this shows that the relation between these two based on reciprocity norm is universal. Shore and Tetrick (1991) found that financial support is linked more with the moral aspect of commitment and employees feel morally obligated to commit to the organization due to this kind of support.

Previous research studies suggest that when the work of employees gets acknowledged, their desire for self-respect, acceptance, and sense of belonging is fulfilled. This leads them to believe that their work is appreciated, valued, and rewarded and it will reoccur in the future which lead to greater effort on their part (Shore et al., 1995). Satisfying their self-esteem, acceptance and belonging needs make them feel proud as a part of the organization (Meyer \& Allen, 1991). Employees who believe their efforts are not recognized and appreciated lose interest in their work, absenteeism rises, and some even leave the company because of a lack of perceived organizational support. (Eisenberger et al., 1997). Some of the factors that significantly contribute towards building the perception of employees about organizational support are procedural justice, distributive justice, and communication (Wayne et al., 2002)

Distributive justice from the perception of employees is the equality and justice in compensation they receive as a result of their services towards the organization. Whether these compensations are following their provided efforts or not. Procedural justice refers to the perception of employees regarding the fairness of the procedure through which these compensations are regulated. (Yoon, 2002).

The emotional aspect of commitment is found to be strongly correlated with the perception of employees about the extent of fairness of organizational human resource policies. If they believe that the policies are placed to maintain equality and justice for the employees, they will get more dedicated towards their organization (Koys, 1991). Studies have found a strong positive relationship between perceived organizational support and distributive and procedural justice. Equity and fairness make the perception in the employee that the organization cares about their welfare (Wayne et al., 2002). 
Employees who participate in decision-making would most likely contribute more and help in achieving the organizational goals as this will improve their perception towards organizational support and increase their commitment (Eisenberger et al., 2002).

Allen (1992) found the same effect of genuine and clear top management communication with employees. His study suggests that important decisions about work that resulted from impartial, fair, and precise information affects organizational support. Similarly, when every employee has been given the right to contribute and communicate openly, this increases organizational support and commitment. Clear and proper communication about the organization's practices and policies are found to positively impact the performance of employees. Communication about the goals and strategies by the upper-level management to the lower-level employees can lead to high levels of perceived organizational support. If goals and strategies are not communicated properly, it can result in a difference between actual strategies and the perception of employees about the strategies (Neves \& Esenberger, 2012).

H2: Perceived organizational support has a positive impact on organizational commitment.

\section{Organizational Values System}

Employees within an organization assess the benchmark set in work surroundings about what is right and appropriate and then they estimate what is the significance of adopting the preferred standards. The perceived standards or their evaluated significance are organizational values as perceived by the employees (Dose, 1997).

Synchronization between personal and organizational values has gained popularity among researchers. Studies have found that most people would prefer an organization with values such as equity, tolerance, coordination, support. Employees of such organizations that implement these values have higher levels of affective commitment towards their organization. Similarly, organizations with strong values related to goal achievements and visions like growth and development, openness, and creativity, and taking initiatives to enhance the level of affective commitment of their workforce through their values. This is because most people prioritize these values. People with the same values as the organization have higher levels of commitment towards the organization. The moral aspect of commitment of employees was found higher in individuals who prioritize adhesion to formality, alertness, and compliance (Finegan, 2000). 
Lankau et al. (2007), found in their study which was conducted on top management employees, that differences in the significance of organizational values perceived by other members from the ones of CEO can result in task and relationship conflict, and if the difference is between the members of top-level management other than $\mathrm{CEO}$, this results in relationship conflict.

Schwartz and Bardi (2001) conducted a study to find that there are universal human values, and these values guide people's actions and attitudes. If something or someone opposes these values, any human would react unpleasantly to it. The reason for the same values followed universally is their adaptive features. Humans to survive and fit in the society adapt values to fulfill these goals, "cooperative and supportive primary relations, productive and innovative task performance, and gratification of self-oriented needs and desires." This indicates that humans adapt values with time to survive and conform with society, so they practice it in the workplace as well.

In this regard, Posner (2010) found strong evidence which signifies that as an employee gains experience and spends years in an organization, their values get aligned with the values of an organization and they understand the values of the organization more clearly with time. This shows that a strong values system may help employees understand the values of the organization better and earlier. This increases their commitment to the organization. He suggests that organizations should hire such people with similar values or if employees compromise to conform with the existing organizational values, the organization should appreciate their efforts. His research also shows that values have a role in maintaining workplace productivity and in increasing the motivation and efficiency of the workforce.

Similarly, a study conducted by Howell et al. (2012), suggests that if the company has some policies and values, they have adopted but do not practice, it will negatively influence the work attitude of employees, and their affective commitment decreases as their trust in the company's integrity decrease. If a company implements a clearly defined and strong value system, it increases the commitment of employees. If employees properly understand and work in an environment with proper implementation of values, it will positively affect organizational performance.

However, Abbott et al. (2005) argued in their study that two main forces drive workplace behavior, one is the values that drive the behavior of individuals, other is the commitment. They carried out the study in different organizations with different cultures and found that vision and human organizational values related more to affective commitment. They suggested that if an organization has to improve their employee's workplace behavior and align their values with the ones of the 
organization, they must reward their employees to practice organizational values. Dylag (2013) conducted a study in polish organizations of different sectors. He found out that dissimilarity between personal and organizational values leads to professional burnout and a decrease in work engagement.

Contrarily, Fitzgerald et al. (2004) in their research emphasized that a clearly defined organizational value system and proper communication of values not only increases the commitment but employees in such organizations perceive that they are more involved in the decisions making of their organization and are more involved in their organization itself, which give them confidence and motivation.

H3: Organizational values systems have a positive impact on organizational commitment.

\section{THEORETICAL FRAMEWORK}

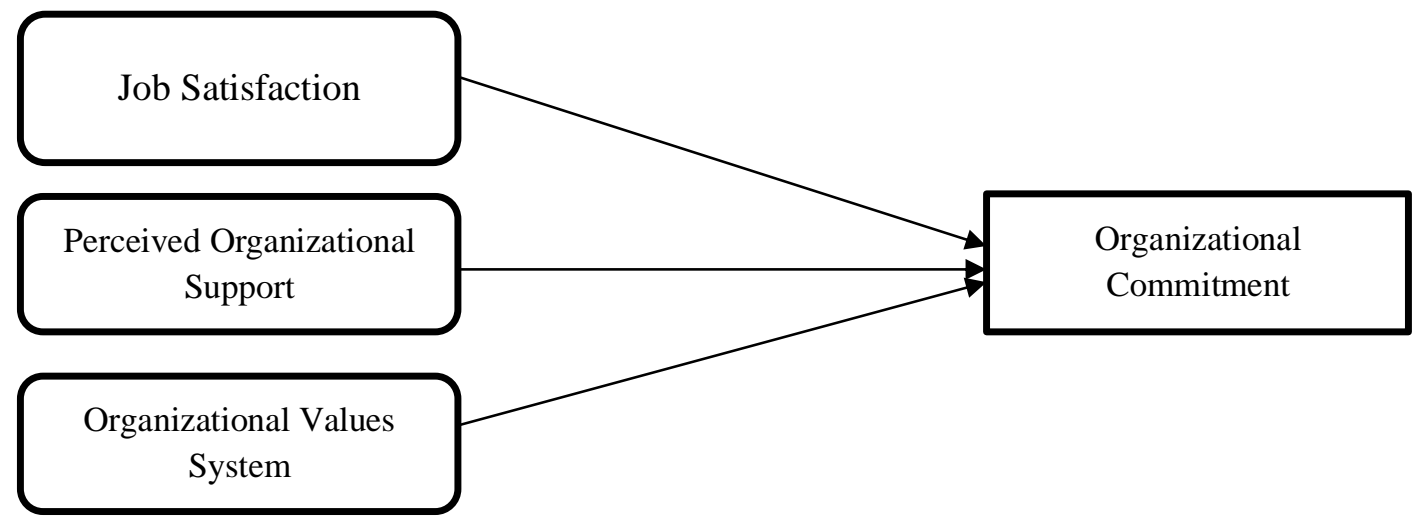

Figure 1. Theoretical Framework

\section{METHODOLOGY}

As of today, there are $124 \mathrm{HEC}$ recognized universities operating in Pakistan. 89 of them are public sector universities and 35 of them belong to the private sector. 23 of them are working in different areas across Islamabad. Teachers at universities operating in Islamabad were surveyed concerning the impact of job satisfaction, perceived organizational support, and organizational values system on organizational commitment. The main focus of the study was on the respondents from universities across the capital city. To conduct the given research and test the formulated model, quantitative analysis was adopted. As the model can be more precisely tested through quantitative 
analysis, this approach was more appropriate. Due to a shortage of time and resources, a convenient sampling technique was used to collect samples. Among the 350-questionnaire distributed, a total of 210 questionnaires were returned by the close-out date which signifies a $60 \%$ response rate. 10 of 23 universities responded to our request. The data was collected within the year 2020-21. After filtering out the unfilled and improper responses, the final sample size subjected to analysis was 200.

The study was conducted in the educational sector and the respondents were among 10 universities namely Bahria University, Islamic International University, Riphah University, National Defence University, Air University, Federal Urdu University, Comsats, University of Lahore, National University of Science, and Technology, Quaid-e-Azam University. The data was collected through Google doc questionnaires sent out via email. The study was conducted using the cross-sectional method to analyze the impact at a specific point in time. The analysis of data collected for testing of hypotheses was facilitated by the use of SPSS 22.0 software. SPSS software was used to analyze the data and evaluate the impact of determinants on organizational commitment through regression analysis. Regression analysis generates more reliable results when it comes to testing the impact of variables. The relation among all variables is also studied through correlation analysis.

\section{Measurement Instruments}

Measures used for questions were composed of 5 points Likert-type scale on which the respondents were instructed to indicate the degree of their agreement with each item, 1 strongly disagreeing with the statement, and 5 strongly agreeing with it. For the demographic section, nominal and ordinal scales were used. Age, gender, and qualifications are used as control variables. Hence, organizational commitment was a 4-item scale adapted from Yoon and Thye (2002). The initial scale was acquired from Mowday (1982). Job satisfaction was a 5-item scale adapted from Yoon and Thye (2002) and its initial scale was acquired from Brayfield and Rothe (1951). The third construct perceived organizational support was a 4-item scale adapted from Yoon and Thye (2002) and its initial scale was acquired from Eisenberger et al. (1986). Lastly, organizational values system was 7-item scale adapted from Boxx, Odom, and Dunn (1991).

\section{Sampling Characteristics}

The sample of the study has the following statistical characteristics. This includes gender, age, and qualification. 
Table 1. Demographic Profile

\begin{tabular}{ccc}
\hline Demographic Variable & Type & Percentage\% \\
\hline Gender & Male & 53.5 \\
& Female & 46.5 \\
\hline Age & Less than 25 & $8 \%$ \\
& $26-30$ & $20 \%$ \\
& $31-35$ & $19.5 \%$ \\
& $36-40$ & $29 \%$ \\
& $41-45$ & $12.5 \%$ \\
& $46-50$ & $3.5 \%$ \\
& 50 or above & $7.5 \%$ \\
\hline Qualification & Bachelors & $8 \%$ \\
& Masters & $12.5 \%$ \\
& MS/M.Phil. & $41 \%$ \\
& Doctoral & 38.5 \\
\hline
\end{tabular}

The highest number of correspondents belong to the 36-40 years old age group as compared to other groups, with $28.8 \%$ response. The second-highest number of respondents belong to the 31 35 years old age group with 19.7\% responses and 26-30 age group also have the same percentage. Whereas, 41-45 years old age group had a response rate of $12.1 \%$ and others with even lower percentages. Universities mostly hire individuals with $\mathrm{Ph} . \mathrm{D}$. or M.Phil. degrees and good experience, which signifies that the age group of teachers would mostly be older. This can be seen in the qualification column as well, as the highest percentage of respondents belong to M.Phil. (39.9\%) and Ph.D. degrees (39.4\%). The respondents were male (46.5\%) and female (53.5\%) in almost equal proportions. It indicates that both genders serve equally in this sector.

\section{RESULTS}

\section{Correlation \& Regression Analysis}

After the data collection, the regression and correlation analysis was done on the collected data through SPSS to find out the accuracy, reliability, and fitness of the model and variables. It was also performed to find out the empirical findings of the study.

Table 2 demonstrates the reliabilities of variables in parenthesis. The reliabilities of all variables were above the conventional standards except organizational commitment. Reliability of job satisfaction is .800 , of perceived organizational support .794 , organizational values system .847 and for the organizational commitment, the reliability was .606. 
The internal consistency and reliability of variables are measured by Cronbach's alpha (Nunnally, 1978). The values that are usually acceptable for Cronbach alpha ranges from 0.70 to 1 (Nunnally, 1978). However, values around .60 are also acceptable, especially if the factor has only a few items (Hair, 2006).

The correlation found among the dependent and independent variables is shown in table 2. As shown in the table, a strong and positive relationship has been found between job satisfaction and organizational commitment, with the correlational value of $r=0.427^{* *}$. Similarly, there is a significant positive relationship between perceived organizational support and organizational commitment, and organizational values system and organizational commitment with the values of $\mathrm{r}=0.224 * *$ and $\mathrm{r}=0.251 * *$.

Table 2. Mean, Standard Deviations, Correlations, and Reliability

\begin{tabular}{lcccccc}
\hline Variables & Mean & Std. Deviation & $\mathbf{1}$ & $\mathbf{2}$ & $\mathbf{3}$ & $\mathbf{4}$ \\
\hline 1). Organizational Commitment & 4.1500 & .63553 & $(.606)$ & & & \\
\hline 2). Job Satisfaction & 4.0680 & .62653 & $.427^{* *}$ & $(.800)$ & & \\
\hline 3). Organizational Values System & 3.9514 & .60430 & $.251^{* *}$ & $.240^{* *}$ & $(.847)$ & \\
\hline 4). Perceived Organizational Support & 3.4713 & .74186 & $.224^{* *}$ & $.295^{* *}$ & $.417^{* *}$ & $(.794)$ \\
\hline
\end{tabular}

$n$ - 200, Cronbach's alphas presented parenthesis. ${ }^{* *} p<0.01$ (2-tailed) $* p<0.05$ (2-tailed)

\section{Regression Analysis}

This analysis looks into the impact of job satisfaction, perceived organizational support, and organizational values system over organizational commitment. $\mathrm{R}$ squared in the regression model represents the percentage change in the dependent variable. The percentage of the dependent variable, which is defined by independent variables significantly, is indicated by $\mathrm{R}$ squared. The beta coefficient shows the strength of association of independent with the dependent variable and significance defines the accuracy and correctness of results by ** signs.

It was established through the results that perceived organizational support, organizational values system, and job satisfaction significantly and positively influence organizational commitment. The impact of perceived organizational support on organizational commitment is shown by $\beta=0.192$, significance $p<0.001 * * *, R 2=0.050$. The impact of organizational values on organizational commitment is signified with $\beta=0.264$, the significance of $p<0.001^{* * *}$ and $R 2=0.063$, and job satisfaction is indicated by $\beta=0.433$, the significance of $p<0.001 * * *$ and $R 2=0.182$. 
Table 3. Multiple Regression Analysis

\begin{tabular}{lccc}
\hline & & Organizational Commitment & \\
\hline Variables & $\boldsymbol{\beta}$ & $\mathbf{R}^{\mathbf{2}}$ & Adjusted $\mathbf{R}^{\mathbf{2}}$ \\
\hline Job Satisfaction & $0.433^{* * *}$ & 0.182 & 0.178 \\
\hline Organizational Value & $0.264^{* * *}$ & 0.063 & 0.058 \\
\hline Perceived Organizational Support & $0.192^{* * *}$ & 0.050 & 0.046 \\
\hline$* * * p<0.001 * * p<0.01 * p<0.05 p<0$. & &
\end{tabular}

The positive and significant impact of job satisfaction, perceived organizational support, and organizational values system on organizational commitment prove our hypotheses.

Table 4. Results Summary

\begin{tabular}{clc}
\hline S\# & Hypothesis & Results \\
\hline H1 & $\begin{array}{l}\text { Job satisfaction has a positive impact on Organizational } \\
\text { Commitment. }\end{array}$ & Confirmed/Significant \\
\hline H2 & $\begin{array}{l}\text { Perceived organizational support has a positive impact on } \\
\text { Organizational Commitment. }\end{array}$ & Confirmed/Significant \\
\hline H3 & $\begin{array}{l}\text { Organizational Values System has a positive impact on } \\
\text { Organizational Commitment. }\end{array}$ & Confirmed/Significant \\
\hline
\end{tabular}

\section{DISCUSSION AND CONCLUSION}

\section{Discussion}

In organizational settings, the organizational commitment of employees plays an important role in the success and achievement of strategic aims. The most valuable asset a company can have is a dedicated and motivated workforce. This study focuses on the factors that impact organizational commitment like job satisfaction, perceived organizational support, and organizational values system, to facilitate organizations build the long-term commitment of their employees. The objective of the study was to find the strength of the relation between job satisfaction, perceived organizational support, organizational values, and organizational commitment. It also aimed to find the significance of these factors in the development of the organizational commitment of employees.

Given the results of regression analysis, it is proven that there exists a significant positive relationship between job satisfaction and organizational commitment. The hypothesis that job satisfaction has a significant impact on commitment has been proved, which is consistent with the results of a recent study by Gopinath (2020). According to their findings job satisfaction and organizational commitment play an important role in employee performance and they contribute 
towards commitment to a very high percentage as well. Our hypothesis signifies that in Pakistan if an employee is satisfied with his job through extrinsic and intrinsic rewards, he will be more motivated, more committed, and more dedicated to his work. If the employee would feel that they are satisfied with their jobs and get recognized and rewarded for their efforts through financial and non-financial rewards, they contribute more towards their works, they become more loyal towards the organization and put more efforts towards the achievement of company goals.

In Pakistani culture, work is often associated with wealth and material gains. People mostly look for such jobs and dedicate their efforts where they find the opportunity to get good enough rewards especially financial rewards against their efforts. This could be driven by the low standard of living and joint family culture. To meet the needs, they search for such jobs and get satisfied if their needs are met. This led to higher commitment and efforts on their part to achieve higher rewards and bonuses in the future. In universities, teachers put more effort due to different kinds of rewards they receive which increase their satisfaction, including compensation benefits, paid vacations, and leave.

According to the results in table 3, the impact of perceived organizational support on organizational commitment is positive and significant which proves the second hypothesis. This shows that as an employee perceives that their organization support them, recognize their efforts, and value them, they tend to put more effort and show more loyalty towards the organization. In a university setting, it shows that if the teachers and faculty members feel supported by the university, they can contribute more by putting efforts into providing higher quality education and easing the path of their organizations towards success. Due to better education, universities can get to higher ranks, gain more students, and higher revenues. Afif (2018) confirming this hypothesis argued that if the employees get the needed support from the organization, they will participate in planning and setting the goals of the organization and help achieve them in the long term.

However, in the Asian, particularly Pakistan context, due to high power distance and little interaction between managers and employees, employees find it difficult to communicate their issues and problems openly (Khan, 2018). In absence of organizational support, they may get discontented and detached from the organization without communicating the reason, making the support important for commitment.

The positive and significant impact of organizational values system on organizational commitment has been proven by the regression analysis as well which confirms the third hypothesis. It signifies 
that the stronger the values of an organization and the more they are clearly defined and followed, the more commitment its employees develop. In our culture, when managers/supervisors define the values and standards of the organization, all the subordinates have to strictly follow them. It can be said that this factor is the result of centralized decision-making and risk-averse culture (Khan, 2018). Simply put, if the manager builds a stronger values system across employees through communicating and defining them properly, they may be able to develop a higher level of commitment among employees. Demirtas (2018), had similar findings in his research, consistent with our conclusion.

Although significant, the impact of organizational support and organizational values as indicated by the $\mathrm{R}$ squared values, is still weak. The reason could be the money-oriented culture as mentioned above. Financial rewards are associated more with work and putting effort into work. People feel more motivated and are more devoted towards their work when they are rewarded financially and may not be as motivated when supported emotionally or in other ways.

\section{Conclusion}

We constructed and designed a new framework of organizational commitment incorporating three different research topics that are job satisfaction, perceived organizational support, and organizational values system. Previous researches focused on these topics separately. Our framework suggests that as the employee becomes satisfied with his job, receives adequate support, and clearly understands the values of the company they feel like an important part of the organization. They follow the values and put more effort into their work. Organizations need to implement practices that integrate these factors to strengthen the relationship between the organization and its employees. Our study and results provide a base to build such practices and policies that embodies commitment-enhancing elements.

\section{PRACTICAL IMPLICATIONS}

The rapidly changing situation, increasing competition, and globalization has driven companies to boost their productivity and increase their efficiency to compete in a better way. A committed workforce can be considered a huge asset in this regard. Due to this very reason, companies are looking for different factors that can help them in enhancing the commitment of their employees. This can give them a long-term competitive advantage. Specific to the university setting, to achieve a higher quality level of education and progress, competent and dedicated teachers are the most 
crucial asset required. The standard of higher education in Pakistan is way below the acceptable level. The educational institution must maintain a motivated and dedicated workforce to succeed and compete on an international level. Skilled labor available in the country is a source of productivity, economic growth, higher standard of living, and GDP growth. If a university does not generate enough skilled graduates, the country will suffer in long term. Universities should try to make their employees satisfied through different intrinsic and extrinsic rewards to build their commitment. They may provide them maternity leaves, bonuses, raise etc. Similarly, they can commit to the employee to get commitment in return. They can support employees through fair treatment, provision of assistance, and flexibility in case of any emergency or issue or case of any confusion regarding job tasks. They can also develop a proper, clearly defined, and strong values system that helps employees in becoming a permanent part of the organization. The manager/administrative authority can practice them himself to show and set the example to explain the importance. These practices can easily be applied to other settings as well. Organizational commitment is the need of all organizations, and these factors are generally vital for most of them. Any organization which works through human resources to maximize profits in long term will find them useful.

\section{FUTURE RESEARCH RECOMMENDATIONS AND STUDY LIMITATIONS}

While conducting the research, there are a few limitations that came into notice. They can provide a base for future research endeavors. This research was conducted within 3 months. Due to time constraints, many factors could not be taken into consideration. The organizational commitment has been described with a three components model which was presented by Meyer and Allen (1991) and got widely accepted. The three components are not taken into consideration separately in this study. These could provide valuable insights if studied separately. Furthermore, the data collected, although adequate for the determined sample size, could be more. Large samples generate more accurate results.

Another drawback of the study, which was a result of a short time, is that it was conducted using a cross-sectional method. Longitudinal studies are much more accurate and take into account the changes in the environment that occur over time. Similarly, we have not considered the moderating effect of work autonomy which weakens the relationship between perceived organizational support 
and organizational commitment. This could be one of the reasons for the weak impact between them. Further studies should be done including this variable (Aube et a., 2007).

Moreover, some factors like supervisor support and coworker support which are relatively new as mentioned by Aube et al. (2007) can be taken into consideration while selecting or designing the scale of perceived organizational support for future research. Mediating variables were not taken into consideration in this study which aids in describing the relation between dependent and independent variables in a much better way. 


\section{REFERENCES}

Abbott, G. N., White, F. A., \& Charles, M. A. (2005). Linking values and organizational commitment: A correlational and experimental investigation in two organizations. Journal of occupational and organizational psychology, 78(4), 531-551.

Abid, G., Shaikh, S., Asif, M. F., Elah, N. S., Anwar, A., \& Butt, G. T. H. (2021). Influence of perceived organizational support on job satisfaction: Role of proactive personality and thriving. Int. J. Entrep, 25, 1-11.

Afif, A. H. (2018). The relationship between perceived organizational supports with job satisfaction and organizational commitment at faculty members of universities. Sleep and Hypnosis (Online), 20(4), 290-293.

Ahuja, M., Chudoba, K. M., George, J. F., Kacmar, C., \& McKnight, H. (2002, January). Overworked and isolated? Predicting the effect of work-family conflict, autonomy, and workload on organizational commitment and turnover of virtual workers. In Proceedings of the 35th Annual Hawaii International Conference on System Sciences (pp. 3586-3593). IEEE.

Allen, M. W. (1992). Communication and organizational commitment: Perceived organizational support as a mediating factor. Communication Quarterly, 40(4), 357-367.

Alshmemri, M., Shahwan-Akl, L., \& Maude, P. (2017). Herzberg's two-factor theory. Life Science Journal, 14(5), 12-16.

Altindis, S. (2011). Job motivation and organizational commitment among the health professionals: A questionnaire survey. African Journal of Business Management, 5(21), 8601-8609.

Alutto, J. A., Hrebiniak, L. G., \& Alonso, R. C. (1973). On operationalizing the concept of commitment. Social Forces, 51(4), 448-454.

Angle, H. L., \& Perry, J. L. (1983). Organizational commitment: Individual and organizational influences. Work and Occupations, 10(2), 123-146.

Aube, C., Rousseau, V., \& Morin, E. M. (2007). Perceived organizational support and organizational commitment. Journal of managerial psychology.

Aydogdu, S., \& Asikgil, B. (2011). An empirical study of the relationship among job satisfaction, organizational commitment, and turnover intention. International review of management and marketing, 1(3), 43. 
Bhuian, S. N., \& Mengue, B. (2002). An extension and evaluation of job characteristics, organizational commitment, and job satisfaction in an expatriate, guest worker, sales setting. Journal of Personal Selling \& Sales Management, 22(1), 1-11.

Boxx, W. R., Odom, R. Y., \& Dunn, M. G. (1991). Organizational values and value congruency and their impact on satisfaction, commitment, and cohesion: An empirical examination within the public sector. Public Personnel Management, 20(2), 195-205.

Brayfield, A. H., \& Rothe, H. F. (1951). An index of job satisfaction. Journal of applied psychology, 35(5), 307.

Butt, G., \& Lance, A. (2005). Secondary teacher workload and job satisfaction: do successful strategies for change exist?. Educational Management Administration \& Leadership, 33(4), 401-422.

Caldwell, D. F., Chatman, J. A., \& O'Reilly, C. A. (1990). Building organizational commitment: A multi-firm study. Journal of Occupational Psychology, 63(3), 245-261.

Cheung, C. K. (2000). Commitment to the organization in exchange for support from the organization. Social Behavior and Personality: an international journal, 28(2), 125-140.

Chughtai, A. A., \& Zafar, S. (2006). Antecedents and consequences of organizational commitment among Pakistani university teachers. Applied HRM Research, 11(1), 39.

Coelho, F., \& Augusto, M. (2010). Job characteristics and the creativity of frontline service employees. Journal of Service Research, 13(4), 426-438.

Cooper-Hakim, A., \& Viswesvaran, C. (2005). The construct of work commitment: Testing an integrative framework. Psychological Bulletin, 131(2), 241.

Currie, P., \& Dollery, B. (2006). Organizational commitment and perceived organizational support in the NSW police. Policing: an international journal of police strategies \& management.

Dalal, R. S. (2005). A meta-analysis of the relationship between organizational citizenship behavior and counterproductive work behavior. Journal of applied psychology, 90(6), 1241.

Demirtas, Z. (2018). The Relationships between Organizational Values, Job Satisfaction, Organizational Silence and Affective Commitment. Online Submission, 4(11), 108-125. 
Dose, J. J. (1997). Work values: An integrative framework and illustrative application to organizational socialization. Journal of occupational and organizational psychology, 70(3), 219-240.

Dyląg, A., Jaworek, M., Karwowski, W., Kożusznik, M., \& Marek, T. (2013). The discrepancy between individual and organizational values: Occupational burnout and work engagement among white-collar workers. International Journal of Industrial Ergonomics, 43(3), 225-231.

Eisenberger, R., Cummings, J., Armeli, S., \& Lynch, P. (1997). Perceived organizational support, discretionary treatment, and job satisfaction. Journal of applied psychology, 82(5), 812.

Eisenberger, R., Huntington, R., Hutchison, S., \& Sowa, D. (1986). Perceived organizational support. Journal of Applied psychology, 71(3), 500.

Eisenberger, R., Stinglhamber, F., Vandenberghe, C., Sucharski, I. L., \& Rhoades, L. (2002). Perceived supervisor support: contributions to perceived organizational support and employee retention. Journal of applied psychology, 87(3), 565.

Elizur, D., \& Koslowsky, M. (2001). Values and organizational commitment. International Journal of Manpower.

Farrell, D., \& Rusbult, C. E. (1981). Exchange variables as predictors of job satisfaction, job commitment, and turnover: The impact of rewards, costs, alternatives, and investments. Organizational behavior and human performance, 28(1), 78-95.

Fatima, A., Iqbal, M. Z., \& Imran, R. (2013). Organizational commitment and counterproductive work behavior: role of employee empowerment. In Proceedings of the Sixth International Conference on Management Science and Engineering Management (pp. 665-679). Springer, London.

Finegan, J. E. (2000). The impact of personal and organizational values on organizational commitment. Journal of Occupational and Organizational Psychology, 73(2), 149-169.

Fitzgerald, G. A., \& Desjardins, N. M. (2004). Organizational values and their relation to organizational performance outcomes. Atlantic Journal of Communication, 12(3), 121145.

Gopinath, R. (2020). Impact of Job Satisfaction on Organizational Commitment among the Academic Leaders of Tamil Nadu Universities. GEDRAG \& Organisatie Review, 33(2), 2337-2349. 
Hackman, J. R., \& Oldham, G. R. (1974). The Job Diagnostic Survey: An instrument for the diagnosis of jobs and the evaluation of job redesign projects.

Hair, J., Black, W., Babin, B., Anderson, R., \& Tatham, R. (2006). Multivariate Data Analysis (6th ed.). New Jersey: Pearson Educational, Inc.

Haroon, A., \& Shakil, T. (2021). Gauging the Effect of Job Enrichment on Employee Performance with the Mediating Role of Employee Motivation: Evidence from Private Banking Sector of Pakistan. Journal of Entrepreneurship, Management, and Innovation, 3(1), 135 - 146.

Herzberg, F. (1968). One more time: How do you motivate employees.

Howell, A., Kirk-Brown, A., \& Cooper, B. K. (2012). Does congruence between espoused and enacted organizational values predict affective commitment in Australian organizations?. The International Journal of Human Resource Management, 23(4), 731-747.

Hunt, S. D., Chonko, L. B., \& Wood, V. R. (1985). Organizational commitment and marketing. Journal of Marketing, 49(1), 112-126.

Ivancevich, J. M., Matteson, M. T., \& Konopaske, R. (1990). Organizational behavior and management.

Iverson, R. D., \& Roy, P. (1994). A causal model of behavioral commitment: Evidence from a study of Australian blue-collar employees. Journal of Management, 20(1), 15-41.

Khan, A. H., \& Mahmood, N. (1997). Education in Pakistan: Fifty Years of Neglect [with Comments]. The Pakistan development review, 647-667.

Khan, M. A., \& Law, L. S. (2018). The role of national cultures in shaping the corporate management cultures: A three-country theoretical analysis. Organizational Culture.

Khan, T. I., Jam, F. A., Akbar, A., Khan, M. B., \& Hijazi, S. T. (2011). Job involvement as a predictor of employee commitment: Evidence from Pakistan. International Journal of Business and Management, 6(4), 252.

Koys, D. J. (1991). Fairness, legal compliance, and organizational commitment. Employee Responsibilities and Rights Journal, 4(4), 283-291.

Lankau, M. J., Ward, A., Amason, A., Ng, T., Sonnenfeld, J. A., \& Agle, B. R. (2007). Examining the impact of organizational value dissimilarity in top management teams. Journal of Managerial Issues, 11-34. 
Levinson, H. (1965). The relation between man and Organization. Administrative science quarterly, 9(4), 370-390.

Lincoln, R., \& Kalleberg, A. L. (1990). Culture, Control, and Commitment: A Study of Work Organization and Work Attitudes.

Liu, E. (2019). Occupational self-efficacy, organizational commitment, and work engagement. Social Behavior and Personality: an international journal, 47(8), 1-7.

Locke, E. A. (1976). The nature and causes of job satisfaction. Handbook of industrial and organizational psychology. Chicago: RandMc Narlly, 2(5), 360-580.

Luthans, F. (1992), Organizational Behavior, Sixth Edition, New York: Mc Graw Hill, Inc.

Malik, M. E., Nawab, S., Naeem, B., \& Danish, R. Q. (2010). Job satisfaction and organizational commitment of university teachers in the public sector of Pakistan. International journal of business and management, 5(6), 17.

Markovits, Y., Davis, A. J., \& Van Dick, R. (2007). Organizational commitment profiles and job satisfaction among Greek private and public sector employees. International Journal of Cross-Cultural Management, 7(1), 77-99.

Martin, M. J., \& Kaufman, E. K. (2013). Do job satisfaction and commitment to the organization matter when it comes to retaining employees?

Mathur, G., \& Salunke, M. (2013). Organizational commitment and Job Satisfaction: A study of the Manufacturing Sector. Apotheosis-Tripude's National Journal of Business Research (TNBJR), 4(1), 129-143.

Mayer, R. C., \& Schoorman, F. D. (1998). Differentiating antecedents of organizational commitment: A test of March and Simon's model. Journal of Organizational Behavior: The International Journal of Industrial, Occupational and Organizational Psychology and Behavior, 19(1), 15-28.

Meyer, J. P., \& Allen, N. J. (1991). A three-component conceptualization of organizational commitment. Human resource management review, 1(1), 61-89.

Miao, Q., Newman, A., Sun, Y., \& Xu, L. (2013). What factors influence the organizational commitment of public sector employees in China? The role of extrinsic, intrinsic, and social rewards. The International Journal of Human Resource Management, 24(17), 3262-3280. 
Millette, V., \& Gagné, M. (2008). Designing volunteers' tasks to maximize motivation, satisfaction, and performance: The impact of job characteristics on volunteer engagement. Motivation and Emotion, 32(1), 11-22.

Mottaz, C. J. (1988). Determinants of organizational commitment. Human Relations, 41(6), 467482.

Mowday, R. T. (1982). Expectancy theory approaches to faculty motivation. New Directions for Teaching and Learning, 1982(10), 59-70.

Mueller, C. W., Boyer, E. M., Price, J. L., \& Iverson, R. D. (1994). Employee attachment and noncoercive conditions of work: The case of dental hygienists. Work and Occupations, 21(2), 179-212.

Neves, P., \& Eisenberger, R. (2012). Management communication and employee performance: The contribution of perceived organizational support. Human performance, 25(5), 452464.

Noor, A. (2009). Examining organizational citizenship behavior as the outcome of organizational commitment: a study of universities teachers of Pakistan. Proceedings 2nd CBRC, Lahore, Pakistan.

Norton, M. S. (1998). Teacher absenteeism: A growing dilemma in education. Contemporary Education, 69(2), 95.

Nunnally, J. C. (1978). Psychometric theory. New York: McGraw-Hill Inc.

Porter, L. W., Steers, R. M., Mowday, R. T., \& Boulian, P. V. (1974). Organizational commitment, job satisfaction, and turnover among psychiatric technicians. Journal of applied psychology, 59(5), 603.

Posner, B. Z. (2010). Another look at the impact of personal and organizational values congruency. Journal of Business Ethics, 97(4), 535-541.

Price, J. L., \& Mueller, C. W. (1986). Absenteeism and turnover of hospital employees. JAI Press.

Putti, J. M., Aryee, S., \& Liang, T. K. (1989). Work values and organizational commitment: A study in the Asian context. Human Relations, 42(3), 275-288.

Qureshi, M. I. (2012). Assessment of selected factors on organizational commitment. Gomal University Journal of Research, 28(2), 64-76. 
Rhoades, L., \& Eisenberger, R. (2002). Perceived organizational support: a review of the literature. Journal of applied psychology, 87(4), 698.

Rhoades, L., Eisenberger, R., \& Armeli, S. (2001). Affective commitment to the organization: The contribution of perceived organizational support. Journal of applied psychology, 86(5), 825 .

Schwartz, S. H., \& Bardi, A. (2001). Value hierarchies across cultures: Taking a similarities perspective. Journal of cross-cultural Psychology, 32(3), 268-290.

Sheldon, M. E. (1971). Investments and involvements as mechanisms producing commitment to the organization. Administrative science quarterly, 143-150.

Shore, L. M., \& Tetrick, L. E. (1991). A construct validity study of the survey of perceived organizational support. Journal of applied psychology, 76(5), 637.

Shore, L. M., Barksdale, K., \& Shore, T. H. (1995). Managerial perceptions of employee commitment to the organization. Academy of Management Journal, 38(6), 1593-1615.

Somers, M. J. (1995). Organizational commitment, turnover, and absenteeism: An examination of direct and interaction effects. Journal of Organizational Behavior, 16(1), 49-58.

Sonia, J. (2010). Organizational commitment and job satisfaction: a study of employees in the information technology industry in Bangalore, India (Doctoral dissertation, Christ University).

Spector, P. E. (1986). Perceived control by employees: A meta-analysis of studies concerning autonomy and participation at work. Human Relations, 39(11), 1005-1016.

Staw, B. M., Sutton, R. I., \& Pelled, L. H. (1994). Employee positive emotion and favorable outcomes at the workplace. Organization Science, 5(1), 51-71.

Steers, R. M. (1977). Antecedents and outcomes of organizational commitment. Administrative science quarterly, 46-56.

Tan, T. H., \& Waheed, A. (2011). Herzberg's motivation-hygiene theory and job satisfaction in the Malaysian retail sector: The mediating effect of love of money.

Vancouver, J. B., \& Schmitt, N. W. (1991). An exploratory examination of person-organization fit: Organizational goal congruence. Personnel Psychology, 44(2), 333-352. 
Wayne, S. J., Shore, L. M., Bommer, W. H., \& Tetrick, L. E. (2002). The role of fair treatment and rewards in perceptions of organizational support and leader-member exchange. Journal of applied psychology, 87(3), 590.

Williamson, I. O., Burnett, M. F., \& Bartol, K. M. (2009). The interactive effect of collectivism and organizational rewards on affective organizational commitment. Cross-Cultural Management: An International Journal.

Yao, T., Qiu, Q., \& Wei, Y. (2019). Retaining hotel employees as internal customers: Effect of organizational commitment on attitudinal and behavioral loyalty of employees. International Journal of Hospitality Management, 76, 1-8.

Yoon, J., \& Thye, S. R. (2002). A dual-process model of organizational commitment: Job satisfaction and organizational support. Work and Occupations, 29(1), 97-124. 